\title{
A Problem Solving Interpretation of Argument Analysis
}

\author{
DAVID BERNSTEIN Grand Valley State University
}

Arguments are a pervasive and powerful form of human discourse. It is, therefore, a proper goal of education to teach students how to evaluate the soundness of given arguments. Nevertheless, the standard framework for analyzing and evaluating arguments is limited as a method for teaching critical thinking, I will explore a major limitation of the framework and show how it can be moderated by interpreting arguments as part of a problem solving process. I will then describe some instructional strategies which are suggested by the problem solving perspective.

Ennis (1985) defines critical thinking as "reasonable reflective thinking that is focused on deciding what to believe or do" ( $p$. 45). His defintion is useful for the present argument, since it is widely quoted and because it encompasses thinking processes which extend from skepticism on one end to reasoned belief at the other. Some of these processes take the form of analytical skills necesssary for dissecting arguments and other complex problems. They also include what might be called "constructive", or "generative" skills, such as formulating alternative solutions to a problem or seeing a problem from alternative perspectives.

The standard model of argument analysis calls upon a limited range of the thinking processes entailed by Ennis' definition. Textbooks on the method present a set of skeptical dispositions and analytical skills aimed at defending oneself against claims (e.g. Johnson \& Blair, 1983; Scriven, 1976; Weddle, 1978). 'They teach one how to decide what not to do or believe, but they give little guidance in how to move from skeptical analysis to constructing one's own reasoned belief about the issue at hand. This shortfall in instruction is caused by focusing too directly on the argument itself. An argument is the distillation of thinking about an issue or problem from one perspective. As such, it represents a narrow context, one which highlights issues and considerations which are friendly to the solution being promoted. Someone who wishes to practice critical thinking in the comprehensive sense needs a framework which restores breadth to the considerations which any alternative solution must address. The strength of the problem solving model is that it begins with an attempt to state such considerations.

\section{Demonstrating the Limitations of Argument Analysis}

The goal of analyzing an argument is to make a judgment about its soundness and, hence, how seriously it is to be taken in influencing one's own conduct. The process of evaluating an argument is guided by a strong structural metaphor; it pictures the argument as a scaffolding made of connected assertions. Evaluating the soundness of an argument means probing the structure for empirical and logical weaknesses. Weakly supported reasons can be removed from the structure. Likewise, a connection between the conclusion and supporting reason which is logically loose can be stripped from the structure.

In addition to the external structure of explicit statements, arguments have an intricate internal structure of unstated assertions. Without these assumptions the argument has no standing. Like the assertions 
which make up the visible argument, assumptions can be examined for empirical and logical weaknesses. Those which do not withstand the critical prying and hammering are removed. The architectural metaphor frames the anlaytical strategy clearly: "Work away at each timber and joint of an argument, casting off those which give way."

After wreaking our rhetorical havoc we are confronted with the question of what can be salvaged. In Scriven's (1976) words, "we have to decide, and have good reasons for deciding, how much is left after the demolition work is finished and what it's worth" (p. 186). Textbooks in the area offer one of three options: 1) accepting a now ramshackled structure, but no doubt with several well-informed reservations 2) rejecting the entire argument as unsound 3) salvaging sound pieces from the former structure and building an alternative structure. The first two options tell us what to do with the remains of the argument, but they do not give any direction to formulating our own decision.

Typical presentations of the method of argument analysis bring the enquirer to the point at which only options 1 and 2 are available. Scriven (1976) says: "When these (consequences of our actions) are at stake, you have to decide whether to go with the argument on balance, or against it" (p. 186). Johnson and Blair (1983) are less direct, yet their response just as clearly directs the enquirer to the first two options. After a lengthy anlaysis of an argument on capital punishment, they conclude: "All in all, then, Lafave's argument needs fairly extensive repair before it could be considered compelling" (p. 224).

The approach by Browne \& Keeley (1990) is an exception. It offers one of the most developed procedures among texts of its kind for guiding an enquirer from the point of encountering an argument to the point at which he or she formulates a decision on the issue addressed by the argument.

With the "strong" reasons in hand (those surviving the analysis), the enquirer is now in position to generate alternative conclusions which follow reasonably from those reasons. The only requirement for a legitimate candidate conclusion is that it be consistent with those reasons. The authors make it clear that the same set of reasons can give rise to different inferences only by bringing to bear different assumptions or frames of reference on the reasoning process.

To illustrate the process of generating alternative conclusions from a single reason, imagine that we have analyzed an argument which takes the position that homosexuals should not be hired as public school teachers. ${ }^{2}$ Imagine further that only one reason has survived our analysis: "Since homosexuality is learned, children might be tempted to adopt this lifestyle if it is presented as a harmless option." Let us look at two conclusions which could be generated from the surviving reason. Each conclusion requires certain assumptions in order to be reasonable.

a. Homosexuals should not be permitted to teach in public schools. This is the conclusion reached in the original essay. It requires the assumption that homosexuality is an inappropriate or, more probably, pathological or blasphemous sexual preference.

b. Homosexuals should be hired with the explicit understanding that all discussions of sexuality will be prohibited and that any sexual advances toward students will be grounds for dismissal. This conclusion also accepts the damnation of homosexuality, albeit in milder form. It makes the additional assumption that a teacher can suppress sexuality sufficiently that he or she is not serving as a sexual model for students.

It is part of Brown and Keeley's model that the enquirer chooses the alternative conclusion which is most compatible with his or her value preferences. The authors provide some considerations involved in choosing and justifying one's value preferences. Importantly, the end point of the procedure 
for decision making is to reach a decision which is consistent with the strong reasons and one's values and beliefs related to the issue. Assume, for instance, that I do not approve of homosexuality, yet believe that teachers of good will can keep their sexuality out of relationships with students. Then I would be inclined toward Conclusion $b$, which allows for the hiring of homosexual teachers with the understanding that their sexuality is to be kept strictly out of interactions with students.

Browne and Keeley's approach allows one to accept or reject pieces of an argument rather than necessarily giving the argument an overall passing or failing mark. It comes closer than many other approaches to putting the enquirer on the road to deciding what to believe or do. Nevertheless, it suffers the fault endemic to any approach whose aim is to dismiss parts of an argument. The dismissed part is forgotten. Yet, that bit of argumentation grew out of a general issue which the arguer believed was important for thinking about the problem at hand. It is a mistake in thinking to discard a piece of rejected argument without regard for the general issue to which it is connected. That mistake is believing that one has discredited an idea, because she has discredited the particular form in which it is expressed.

In our example, the concern that teachers might recruit students into homosexual activity is lost because the particular bit of reasoning used to introduce it was judged faulty. However, this concern is likely to be a live one in any real discussion about the issue of whether homosexual teachers should be hired. Simply dropping it from consideration distorts the problem context.

\section{The Problem Solving Framework}

The psychology of problem solving provides an alternative model for reasoning. The following presentation of problem solving is a sketch of the model taken from current cognitive science, especially its underlying assumption.

The model takes as axiomatic that thought and action are embedded in an internal representation of the part of the world to be thought about or acted upon. ${ }^{2}$ Throwing a ball from here to there requires an internal geography of "here" and "there" and a theory of practical physics governing the motion of objects in the external world. Morever, it requires some images about one's body and procedures for moving the body in coordinated and, perhaps, intentional ways. In short people build mental models of the worlds they inhabit. These mental models guide their thoughts and actions.

Extended thinking, such as problem solving or decision making, takes place within a model of the domain one is thinking about. If a person's model of the problem leaves out a crucial element of the situation or if it misrepresents the situation, then her solution will be correspondingly unsatisfactory. One of the earmarks of students who have trouble solving mathematics and science problems is devoting too little attention to building working models of the problem. (Whimbey $\&$ Lochhead, 1984). The importance of representing a problem situation fully and accurately extends into the social sciences. Voss (1983) found that expert sovietologists who were posed the problem of how to increase agricultural productivity in the Soviet Union spent considerably greater time constructing their representations of the problem than did novices in the area.

Solving a problem is often described as a trip through mental problem space. (Simon, 1978). How the problem space is defined depends upon the general issues which the problem solver feels are important. For instance, consider two school board members who are examining alternative curricula for their school system. One board member assumes that the only criterion for judging a prospective cur- 
riculum is how efficiently it teaches basic skills. The other board member accepts that criterion as important, but also believes that a curriculum should provide different cultural groups equal opportunity to succeed in school. The first board member defines the problem space in terms of efficiency alone, whereas the second board member defines it in terms of both efficiency and equity. To the extent that both issues are live ones within the community, the second board member's problem space better represents the world than does the first board member's problem space. And it generates a correspondingly broader range of alternative curriculum proposals. In short, ignoring relevant issues robs the problem space of alternative solutions.

We can use the decision whether to hire homosexual teachers to contrast the problem solving and argument analysis models. It is important to realize that this, like any social problem, will be seen from radically different perspectives. The perspective taken will determine which issues receive attention and which are ignored. For example, the argument of someone with fundamentalist religious beliefs will highlight the issue of how sexual preferences develop and is likely to neglect arguments which address the rights of homosexuals. On the other hand, the argument of an equal rights activist will energetically address the issue of equity, defined as the equal rights of homosexuals to pursue employment.

An important difference between the problem solving model and the argument analysis model is how they respond to such arguments. The argument analysis model directs one to scrutinize an argument for fatal flaws and to exclude flawed parts from the discourse. The problem solving model directs one to examine an argument for what issues it can contribute to the collective problem space. The difference is crucial, because issues are the stuff out of which problem spaces are made. They define the space implicitly by constraining the solutions which are suggested. They define it explicitly, since they become the criteria against which alternative solutions are judged and justified. For example, the equal rights activist might argue for the solution that homosexuals be hired on the same basis as heterosexuals, since such a policy satisfies the criterion of equity better than does the policy of denying jobs to homosexuals. This argument proposes and justifies a solution based on a relatively narrow problem space, defined by only one issue. The field of alternative solutions is correspondingly narrow. It consists of only two alternatives, the one being championed by the arguer and its contradiction.

Consider what happens when the problem space is broadened to include two issues, the issue of how sexual preference develops and the issue of equity. These two issues provide a tension which encourages a search of the problem space for solutions that address both of them. Imagine that this search leads to discovering expert opinion that children of different ages are differentially sensitive to role models in developing a sexual preference. Then some hiring policy might be proposed which differentiates those age groups which homosexuals will and will not teach. As a result, the set of solution alternatives has grown from two to three.

Creating a third position in a polarized discussion is not an easy task. There is a powerful tendency by all discussants to identify a new voice in the discussion with one of two established opposing positions. People in public life know well how much effort it takes to define a position which is different from two established and competing positions. The following example occurred in the 1987 U.S. Presidential preprimary scramble, where declared candidates were trying to establish their own positions on issues. The writer is Bruce Babbitt (1987), a former governor of Arizona. He is addressing the issue of what, if any, steps should be taken to reduce trade imbalances among countries. 
In today"s trade debate, any deviation from laissez faire runs the risk of being labeled protectionist. Several recent reports in The Post have lumped my views with a particular brand of protectionism-the proposal by Rep. Richard Gephardt to punish any nation that fails to reduce its trade surplus with the United States. In fact, I disagree profoundly with that proposal (p. A23).

An enquirer who encounters an argument defending a position faces a similar difficulty. If he is operating within a pure argument analysis model, he gives himself instructions to either agree with the argument or reject it. In both cases, he stays within a narrow representation of the problem space as defined by the argument. How can he go about expanding that representation? The problem solving framework contains a general objective: "Identify all the criteria relevant for judging how satisfactory a solution is." There are several instructional strategies I have used to help students meet that objective.

\section{Instructional Strategies}

The first two strategies are appropriate when the enquirer has in hand only a single argument. As part of the third strategy, the enquirer is directed to find at least two arguments on the same issue.

Strategy 1: Generalize Issues Embedded in the Reasons. A reason for accepting the solution proposed by the arguer is often an assertion that the solution addresses an important issue better than other possible solutions. In some cases, the issue will be mentioned-as was equity in the equal rights activist's argument cited above. More usually, the issue will be assumed.

Consider, for example, a reason from the original argument given by Browne and Keeley: "Since homosexuality is learned, children might be tempted to adopt this lifestyle if it is presented as a harmless option." This reason is embedded in a host of issues, including: a) how a sexual preference develops, b) how sexual preferences are to be "presented" in the classroom and, of course, c) how the appropriateness of various sexual preferences is to be established.

Making any of these issues explicit deepens an understanding of the dynamics within the problem situation. For example, one needs a mental model of the development of gender identity and sexual preference. Constructing such a model means asking questions to establish the relationships. To what extent are these aspects of personality affected by environmental factors as opposed to genetic factors? If environmental factors are important, to what extent are non-parent adult models influential? Do there seem to be critical age periods for the development of sexual identity and/or sexual preference? Answers to these questions have clear bearing on which of several alternative policies is preferable. Tugging on other reasons will unravel similarly complex issues which become either subproblems or criteria which need to be considered. ${ }^{4}$

Strategy 2: Imagining "Voices" Other Than the One That Presents the Argument. The arguer often speaks in a voice representing a particular and narrow perspective. From that point of view, some issues are given greater or lesser prominence than would be given from a different perspective. Such was the case in the imagined voices of the fundamental religionist and equal rights activist. How does an enquirer go about imagining different voices? Sometimes an argument will contain clues to the existence of voices different from the arguer's. Often these occur in the arguer's rebuttal of a competing argument. Individuals or groups which are referenced in the argument are potential sources. What would be a homosexual teacher's viewpoint? Or we might imagine the other possible roles which one could play in the drama. How about a homosexual parent? Summoning these voices is a powerful exercise. They enlarge the discourse by giving additional subproblems to be solved or criteria 
against which alternative policies are to be judged.

Strategy 3: Considering Arguments from Diverse Perspectives. Inducing a more complete problem space from a single argument is difficult and prone to error. The act requires an openness to divergent points of view and an empathy sufficient to summon representative voices for those views. Even with good intentions, imagined arguments are likely to be incomplete and superficial. The arguer is simply not privy to the experience and knowledge possessed by people who truly occupy a different perspective. A more direct route is to find positions on an issue presented by authentic voices. Facing the two arguments towards each other reveals sharp differences in the profiles of issues they address. This strategy can lead directly to a broadening of the problem space, since one argument will often address an issue which is ignored by a second argument. In addition, competing arguments create a dramatic tension on the issues which the arguments address in common. This tension signals the need for clarifying the issue and for negotiating the differences between the two ways of handling the issue.

Strategy 4: Making an argument contrary to one's position. Constructing an argument contrary to one's own position is a powerful strategic move. Within the present problem solving framework, it derives its power from actively engaging the enquirer with issues and evidence which might otherwise be ignored. This is especially true if the issues or evidence are unfriendly to her preferred solution. Active engagement gives information a concreteness and salience in the problem space that can come only from personal involvement. ${ }^{5}$

This strategy is prey to the same pitfalls as the strategy of imagining the voices of others. It is difficult to construct a knowledgeable and lively defense of a position one has in all likelihood previously suppressed. Therefore, the strategy works best when combined with that of considering existing arguments from diverse perspectives.

\section{Summing Up}

This paper began with the claim that argument analysis is seriously limited as an exclusive method for teaching critical thinking. If critical thinking is a journey along some path of deciding what to believe or do, the method of argument analysis takes the enquirer only part way down the path. Its strength is helping the enquirer clear a path through the forest of claims. However, the process of clearing away argumentation often carries away relevant issues which mark the path.

Placing arguments within a problem solving framework guides the enquirer further down the path. The framework provides a language and methodology for extracting relevant issues from the arguments which are encountered along the way. Out of these issues the enquirer can make a more comprehensive map of the problem area. This map defines the various places one can reach in thinking about a problem. And it gives some idea of the relative advantages and disadvantages of each as place to conclude one's journey.

\section{Notes}

1 There are exceptions. One which will be discussed at some length is Asking the Right Questions by Browne \& Keeley (1990). Chafee's (1985) Thinking Critically is a broad instructional program for teaching critical thinking. However, the generalization remains valid that a large number of textbooks used in critical thinking instruction draw primarily on the method of argument analysis.

2 This example is based on a longer argument from Browne \& Keeley. (1990, p. 154).

3 The claim that representation is fundamental to contemporary cogntive psychology, including 
problem solving, can be documented by skimming any current book in the area, especially textbooks. Anderson's (1985) book is one of the most sustained and coherent presentations of that thesis.

This strategy is related to the practice within argument analysis of identifying the assumptions required for a valid inference to be made. Its intent is slightly different. In argument analysis, identifying an assumption frequently leads to discrediting the assumption and, hence, rejecting the bit of reasoning on which it is based as unsound. In the problem solving framework, the intent is to identify issues which all potential solutions must address.

5 Work in the psychology of judgment provides a theoretical basis for the strategy of constructing a contrary position (Lord, Lepper, \& Preston, 1984). Our judgments are biased by events which are part of our recent and immediate experience. These events are primed in our awareness and tend to serve as an anchor for our judgments about the world. Since people generally tend to think about aspects of the problem space which support their solution, those aspects will be primed in memory and, thus, form a biased context for making relative judgments about the quality of alternative solutions. The strategy of constructing an argument for a contrary position will prime a larger structure of knowledge, especially issues and evidence not primed by thinking about their preferred position.

\section{References}

Anderson, J. R. (1985). Cognitive Psychology and its Implications (2nd ed.). New York: W. H. Freeman.

Babbitt, B. (1987). We need multilateral balance. The Washington Post, April 28, A23.

Browne, M. N., \& Keeley, S. M. (1990). Asking the Right Questions: A Guide to Critical Thinking (3rd ed.). Englewood Cliffs, NJ: Prentice-Hall.

Chafee, J. (1985). Thinking Critically. Boston: Houghton Mifflin.

Ennis, R. J. (1985). Goals for a critical thinking curriculum. In A.L. Costa (Ed.), Developing Minds: A Resource Book for Teaching Thinking. Alexandria, VA: Association for Supervision and Curriculum Development.

Johnson, R. H., \& Blair, J. A. (1983). Logical Self-Defense. (2nd ed.) Toronto: McGraw-Hill Ryerson Ltd.

Lord, C.G. . Lepper, M.R. . \& Preston, E. (1984) Considering the opposite: A corrective stragtegy for social judgment. Journal of Personality and Social Psychology, 47, 1231-1243.
Scriven, M. (1976). Reasoning, New York: McGraw-Hill

Simon, H. (1978). Information-processing theory of human problem solving. In W. K. Estes (Ed.), Handbook of Learning and Cognitive Processes: Human Information Processing (Vol. 5). Hillsdale, New Jersey: Erlbaum.

Voss, J. F., Greene, T. R. Post. T. A., \& Penner, B. C. (1983) Problem-solving skill in the social sciences. In G. H. Bower (Ed.), The Psychology of Learning and Motivation: Advances in Research Theory. Volume 17, pp. 165-213. New York: Academic Press.

Weddle, P. (1978). Argument: A Guide to Critical Thinking. New York: McGraw-Hill.

Whimbey, A. \& Lochhead, J. (1984) Beyond Problem Solving and Comprehension: An Exploration of Quantitative Reasoning. Philadelphia: The Franklin Institute Press.

\section{DAVID BERNSTEIN}

PSYCHOLOGY DEPARTMENT GRAND VALLEY STATE UNIVERSITY ALLENDALE, MI 4940I 